\title{
Decreased expression of Small glutamine-rich tetratricopeptide repeat- containing protein (SGT) correlated with prognosis of Hepatocellular carcinoma
}

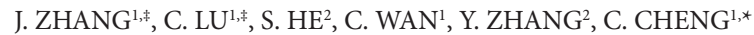

${ }^{1}$ Department of Immunology and Microbiology, Medical College of Nantong University, 19\# Qixiu Road, Nantong, Jiangsu, 226001, P.R. China; ${ }^{2}$ Department of Pathology, Affiliated Cancer Hospital of Nantong University, Medical College of Nantong University, Nantong, P.R. China

${ }^{*}$ Correspondence: cheng_chun@yahoo.com.cn

${ }^{*}$ Contributed equally to this work.

Received January 6, 2013 / Accepted May 27, 2013

\begin{abstract}
Small glutamine-rich tetratricopeptide repeat-containing protein (SGT) is an ubiquitously expressed cochaperone of heat shock cognate protein of $70 \mathrm{kDa}$ (Hsc70). SGT binds to the $\mathrm{C}$ terminus of $\mathrm{Hsc70}$ to recruit Hsc70 into complexes of diverse function. SGTB was identified as an isoform of SGT with $60 \%$ amino acid sequence homology. To investigate the expression of SGTB in hepatocellular carcinoma (HCC) and determine its correlation with tumor progression and prognosis, we evaluated the expression levels of SGTB in HCCs and corresponding adjacent non-tumor liver tissues. We also assessed the association between their expression and clinicopathologic parameters. The expression of SGTB was absent or low in HCCs while it was notable in paracancerous tissues from 108 patients by western blotting and immunochemistry $(P<0.05)$. Among the 108 HCCs, low expression of SGTB was associated with gender, histological grade $(P<0.001)$ and HBsAg expression $(P=0.002)$. Univariate analysis showed that the low SGTB expression was associated with poor prognosis $(P<0.001)$. Thus, decreased expression of SGTB may be a favorable independent poor prognostic parameter for hepatocellular carcinoma.
\end{abstract}

Key words: SGTB, Heat stress cognate 70 (Hsc70), HBV, Hepatocellular carcinoma (HCC)

Hepatocellular carcinoma (HCC) is the fifth most common cancer worldwide, and the third most common cause of cancer mortality $[1,2]$. This tumor, which arises from hepatocytes, is often associated with liver cirrhosis resulting from chronic liver diseases. When intermediate-to-advanced cancer is found at diagnosis, the majority of HCC patients are eligible only for nonsurgical treatment which is less efficacious. Thus detecting $\mathrm{HCC}$ at an earlier stage is important so that the use of curative treatments is possible [3].

Heat shock cognate protein of $70 \mathrm{kDa}(\mathrm{Hsc} 70)$ is a constitutive member of the heat shock-induced Hsp70 protein family. Despite of their high degree of sequence homol-

Abbreviations: HCC: hepatocellular carcinoma; SGT: small glutaminerich tetratricopeptide repeat-containing protein; Hsc70: heat shock cognate protein of $70 \mathrm{kDa}$; Hsp70: heat stress protein 70; CTD: C-terminal domain; ABD: ATP- binding domain; PBD: peptide-binding domain; CHB: chronic hepatitis B; CC: coiled-coil region ogy, Hsp70 is induced by stress (e.g., heat shock) whereas Hsc70 is constitutively expressed in cells. Hsc70 interacts with many other molecules as well and regulates various cellular functions. It is also involved in various diseases such as cancer, cardiovascular, neurological, hepatic and many other diseases [5]. In particular, Hsc70 has been implicated in the pathogenesis and the pathophysiology of hepatic diseases such as hepatitis B and C, nonalcoholic steatohepatitis autoimmune hepatitis, and primary biliary cirrhosis. It plays an important role in the replication of hepatitis B virus (HBV) and hepatitis $\mathrm{C}$ virus (HCV) [5]. Some investigations supported that down regulation of this protein in the host would inhibit HBV replication in either wild-type or drug-resistant strains [6]. Nevertheless knock down of Hsc70 may be not appropriate as the depletion of the major housekeeping chaperone Hsc70 killed tumorigenic as well as nontumorigenic cells [7]. Therefore, we need to find another more specific target in HCC. 
Small glutamine-rich tetratricopeptide repeat-containing protein (SGT) was first identified as a protein putatively interacting with envelope proteins of two viruses, HIV type 1 and parvovirus H-1 [8]. Rat SGT consists of 314 amino acid residues that are arranged in three domains of equal size: an $\mathrm{N}$-terminal region, a central TPR domain, and a C-terminal region. The central TPR domain consists of three repeats, which are sufficient for binding to the $\mathrm{C}$ terminus of Hsc70 [9]. In an in- vitro study, SGT negatively influenced the ability of Hsc70 to refold a denatured model protein substrate [10]. Our data suggested the expression of SGTB, which is an isoform of SGT [11], and a heat-shock protein cognate 70 (Hsc70) co-chaperone [12], showed significant expression difference between normal liver tissue and HCC.

\section{Patients and methods}

Patients and tissue samples. HCC and adjacent non-tumor liver tissues specimens were obtained from 108 patients. All underwent hepatic surgical resection without postoperative systemic chemotherapy at the Surgery Department, the Affiliated Hospital of Nantong University between April 2004 and

Table 1. SGTB expression and clinicopathological parameters in $108 \mathrm{HCC}$ specimens

\begin{tabular}{|c|c|c|c|c|}
\hline \multirow{2}{*}{ Parameters } & \multirow{2}{*}{ Total } & \multicolumn{2}{|c|}{ SGTB } & \multirow{2}{*}{$\mathrm{p}^{\mathrm{a}}$} \\
\hline & & Low & High & \\
\hline \multicolumn{5}{|l|}{ Age(years) } \\
\hline$\leq 50$ & 55 & 44 & 11 & 0.102 \\
\hline$>50$ & 53 & 35 & 18 & \\
\hline \multicolumn{5}{|l|}{ Gender } \\
\hline Male & 86 & 69 & 17 & 0.001 \\
\hline Female & 22 & 10 & 12 & \\
\hline \multicolumn{5}{|c|}{ Histological grade } \\
\hline Well & 11 & 4 & 7 & $<0.001$ \\
\hline Mod & 51 & 31 & 20 & \\
\hline Poor & 46 & 44 & 2 & \\
\hline \multicolumn{5}{|l|}{ Metastasis } \\
\hline Positive & 16 & 14 & 2 & 0.160 \\
\hline Negative & 92 & 65 & 27 & \\
\hline \multicolumn{5}{|c|}{ Tumor size $(\mathrm{cm})$} \\
\hline$\leq 5$ & 63 & 46 & 17 & 0.971 \\
\hline$>5$ & 45 & 33 & 12 & \\
\hline \multicolumn{5}{|l|}{ HBsAg } \\
\hline$(-)$ & 32 & 17 & 15 & 0.002 \\
\hline$(+)$ & 76 & 62 & 14 & \\
\hline \multicolumn{5}{|l|}{ Cirrosis } \\
\hline Positive & 89 & 66 & 23 & 0.609 \\
\hline Negative & 19 & 13 & 6 & \\
\hline \multicolumn{5}{|l|}{$\operatorname{AFP}(\mathrm{ng} / \mathrm{ml})$} \\
\hline$\leq 50$ & 42 & 28 & 14 & 0.225 \\
\hline$>50$ & 66 & 51 & 15 & \\
\hline
\end{tabular}

a Statistical analyses were performed by the Pearson $\chi^{2}$ test. $\mathrm{P}<0.05$ was considered significant.
May 2007. The diagnosis was confirmed histologically in all cases, based mainly on examination of sections stained with $\mathrm{H} \& \mathrm{E}$. The main clinical and pathologic variables of the patients are shown in Table 1. Eighty-six patients were men and twentytwo were women; their ages ranged from 21 to 69 (mean = 54.18 years old). Seventy-six patients were positive for HBV surface antigen, eighty-nine were positive for cirrhosis. Histological grades were classified to well differentiated (grade I), moderately differentiated (grade II), and poorly differentiated (grade III).Of the 108 patients examined, 11 were classified as grade I, 51 were classified as grade II, and 46 were classified as grade III. The main clinicopathological variables of the patients are shown in Table 1. Tissue samples were immediately processed after surgical removal. For histological examination, all tumorous and surrounding nontumorous tissue portions were fixed in formalin and embedded in paraffin. Informed consent was obtained from all patients.

Immunoblot analysis. Tissue and cell protein were promptly homogenized in a buffer containing $1 \mathrm{M}$ Tris- $\mathrm{HCl}$ $\mathrm{pH} 7.5,1 \%$ Triton X-100, 1\% NP-40 (nonidet p-40), 10\% sodium dodecyl sulfate (SDS), $0.5 \%$ sodium deoxycholate, $0.5 \mathrm{MEDTA}, 10 \mathrm{lg} / \mathrm{ml}$ leupeptin, $10 \mathrm{lg} / \mathrm{ml}$ aprotinin, and 1 mMPMSF, then centrifuged at 10,000 $\mathrm{g}$ for $30 \mathrm{~min}$ to collect the supernatant. Protein concentrations were determined with a Bio-Rad protein assay (BioRad, Hercules, CA, USA). The supernatant diluted in $2 x S D S$ loading buffer and boiled. Proteins were separated with SDS-polyacrylamide gel electrophoresis (SDS-PAGE) and transferred to polyvinylidene difluoride filter (PVDF) membranes (Millipore, Bedford, MA). The membranes were blocked with $5 \%$ dried skim milk in TBST (20 $\mathrm{mM}$ Tris, $150 \mathrm{mM} \mathrm{NaCl}, 0.05 \%$ Tween-20). After $2 \mathrm{~h}$ at room temperature, the filters were washed by TBST for three times and then incubated overnight with polyclonal antibody against using the primary antibodies described later and horseradish peroxidase-linked IgG as the secondary antibodies. Immunoreactive bands were visualized by chemiluminescence (NEN Life Science Products, Boston,MA) Antibodies used were as follows: anti-SGTB (AP5076a; 1:500; Abgent); anti- $\beta$-actin (1:4000; Sigma).

Immunohistochemistry(IHC). The sections were deparaffinized using a graded ethanol series, and endogenous peroxidase activity was blocked by soaking in $0.3 \%$ hydrogen peroxide. Thereafter, the sections were processed in $10 \mathrm{mmol} / \mathrm{L}$ citrate buffer ( $\mathrm{pH}$ 6.0) and three minutes of high temperature and pressure to retrieve the antigen. After rinsing in PBS $(\mathrm{pH} 7.2), 10 \%$ goat serum was applied for 1 hour at room temperature to block any nonspecific reactions. After that the sections were incubated overnight at $4{ }^{\circ} \mathrm{C}$ with anti-SGTB rabbit polyclonal antibody (diluted 1:100; Novus Biologicals), Negative control slides were also processed in parallel using a nonspecific immunoglobulin IgG (Sigma Chemical Co., St. Louis, MO) at the same concentration as the primary antibody. All slides were processed using the peroxidase antiperoxidase method (Dako, Hamburg, Germany). After rinsing in PBS, the peroxidase reaction was visualized by incubating the sections 
with diaminobenzidine tetrahydrochloride in $0.05 \mathrm{~mol} / \mathrm{L}$ Tris buffer (pH7.6) containing 0.03\% H2O2. After rinsing in water, the sections were counterstained with hematoxylin, dehydrated, and coverslipped.

Immunohistochemical evaluation. Two observers (Q.K and M.D.L.) independently evaluated the immunostaining results, similar results were obtained in these samples. For assessment of SGTB, five highpower fields in each specimen were selected randomly, and cytoplasma (nuclear) staining was examined under high power magnification. All sections were scored by means of the immunoreactivity score (IRS) according to Remmele \& Stegner [13]. The intensity of immunostaining in each tumor section was assessed as strong (3), moderate (2), weak (1), or negative (0); semi-quantitatively using the following scale: $<10 \%$ of cells (0), $10-30 \%(1), 30-50 \%$ (2), $50-70 \%$ (3), and $>70 \%$ (4) of cells, and then combined these values. This resulted in an overall SGTB immunohistochemical score ranging from 0 to 12 . SGTB expression was considered high when scores were $>3$, and low when scores were $\leq 3$.

\section{Statistical analysis}

Statistical analysis was performed using the SPSS Statistics17.0 software package. SGTB expression in HCCs was studied using the Spearman rank correlation test because the data were not normally distributed. Survival curves were calculated using the Kaplan-Meier method, and the log-rank test was used for analysis. The results of the HCC cells are expressed as the mean \pm SE. $\mathrm{P}<0.05$ was considered statistically significant.

\section{Results}

The expression of SGTB protein in HCC and the adjacent non-tumor liver tissue. Expression of SGTB was first studied

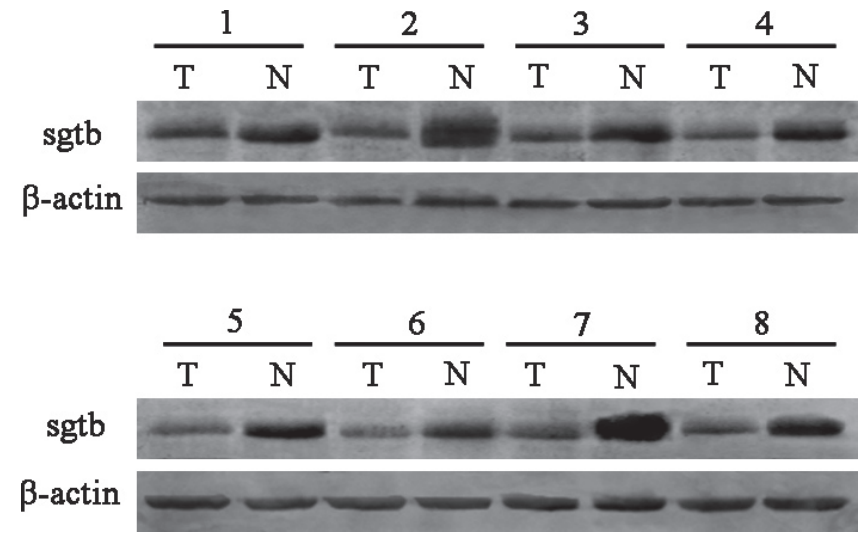

Figure 1. SGTB is low expressed in hepatocellular carcinoma but high in paired adjacent non-tumor liver tissues. Western blot of eight representative paired samples of hepatocellular carcinoma tissue $(\mathrm{T})$ and adjacent non-tumor liver tissues (N) immunoblotted against SGTB. Whole-cell lysates were prepared from tissue specimens obtained from hepatocellular carcinoma and adjacent non-tumor liver tissues. In all samples tested, SGTB expression was obviously lower in hepatocellular carcinoma than in paired adjacent non-tumor liver tissues. $\boldsymbol{\beta}$-actin was used as a control for protein load and integrity.

by immune blotting method in 8 novel specimens, we showed that SGTB expression was different in paired non-tumor liver and HCC biopsy samples, with a dramatically decreased expression in eight tumors compared with the adjacent nontumor liver tissues, (Fig1). In order to identify the expression of SGTB, we further investigated 108 paired tissue samples by immunohistochemistry (Fig2). SGTB immunoreactivity was identified in 99 cases $(91.7 \%)$ of paracancerous tissues, while it was recognized in 29 cases $(26.9 \%)$ of HCCs. SGTB was low expressed or absent in most specimens and mainly in cytoplasm (Fig2a-d) compared with corresponding adjacent
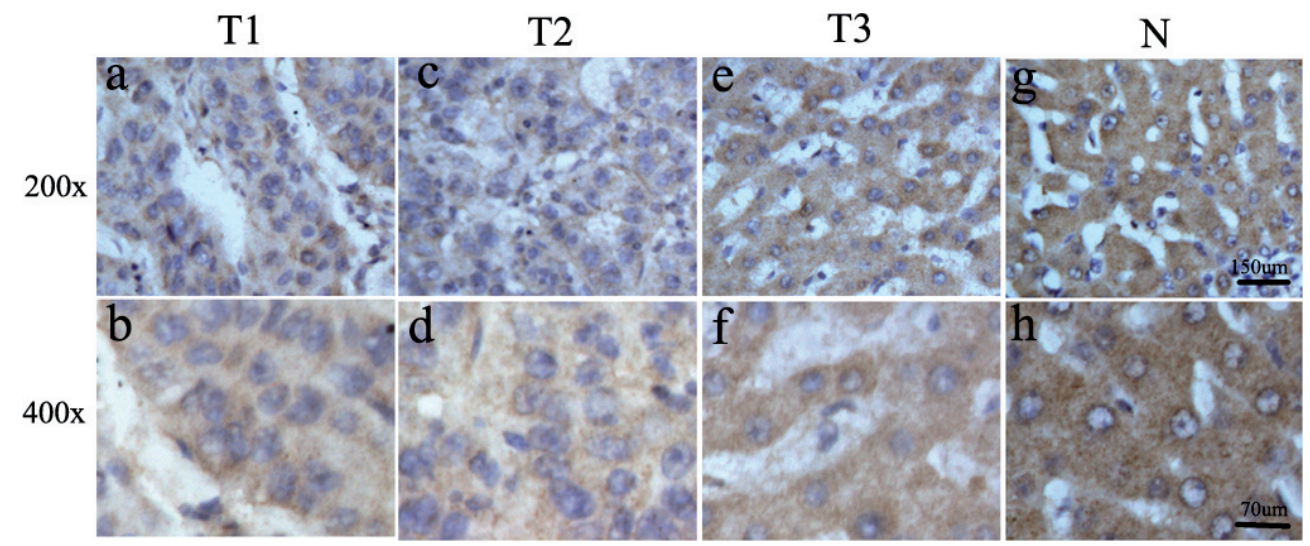

Figure 2. Immunohistochemical staining of SGTB in HCC tissues (a-f) and non-tumor liver tissues ( $g$, h). Paraffin-embedded tissue sections were stained with antibodies for SGTB and counterstained with hematoxylin. (a and c) SGTB weak staining was shown in HCC tissues (200x), (b and d) with staining predominant in the cytoplasm (400×). (e) SGTB strong staining was shown in HCC tissues $(200 \times)$, (f) with staining predominant in the cytoplasm $(400 \times)$. (g) SGTB immunoreactivity was identified in non-tumor liver tissues $(200 \times)$, (h) with staining predominant in the cytoplasm $(400 \times)$. 
liver samples (Fig2g-h), and it was high expressed in only a few specimens (Fig2e-f). This difference indicated that low expression of SGTB may be associated with HCC occurrence.

Correlation between SGTB expression and clinicopathological parameters of HCC. The clinicopathological data of the 108 patients are summarized in Table 1. As shown in Table 1, we evaluated the association of SGTB expression with clinicopathologic parameters. SGTB expression did not correlate with age, metastasis, tumor size, cirrhosis, the level of AFP, but notably correlated with gender, histological grade $(\mathrm{P}<0.001)$ and $\mathrm{HBsAg}(\mathrm{P}=0.002)$ (Table 1). Although the sgtb gene is considered as weakly female specific in mouse liver in some research [14], we haven't find the discrepancy between the male and female human paracancerous liver tissues.

Survival analysis. At the end of clinical follow-up, survival information was available in 90 cases of 108 patients (83.3\%). For statistical analysis of the expression of SGTB, the carcinoma specimens were divided into two groups: high expressors and low expressors, according to the immunohistochemical score using the semi-quantitative immunoreactive score method

Table 2. A. Survival status and clinicopathological parameters in $90 \mathrm{HCC}$ specimens

\begin{tabular}{|c|c|c|c|c|}
\hline \multirow{2}{*}{ Parameters } & \multirow{2}{*}{ Total } & \multicolumn{2}{|c|}{ Survival status } & \multirow{2}{*}{$\mathrm{p}^{\mathrm{a}}$} \\
\hline & & Alive & Dead & \\
\hline \multicolumn{5}{|l|}{ Age(years) } \\
\hline$\leq 50$ & 48 & 25 & 23 & 0.978 \\
\hline$>50$ & 42 & 22 & 20 & \\
\hline \multicolumn{5}{|l|}{ Gender } \\
\hline Male & 74 & 34 & 40 & 0.010 \\
\hline Female & 16 & 13 & 3 & \\
\hline \multicolumn{5}{|l|}{ Histological grade } \\
\hline Well & 10 & 10 & 0 & $<0.001$ \\
\hline Mod & 37 & 23 & 14 & \\
\hline Poor & 43 & 14 & 29 & \\
\hline \multicolumn{5}{|l|}{ Metastasis } \\
\hline Positive & 14 & 4 & 10 & 0.054 \\
\hline Negative & 76 & 43 & 33 & \\
\hline \multicolumn{5}{|l|}{ Tumor size $(\mathrm{cm})$} \\
\hline$\leq 5$ & 50 & 34 & 16 & 0.001 \\
\hline$>5$ & 40 & 13 & 27 & \\
\hline \multicolumn{5}{|l|}{ HBsAg } \\
\hline$(-)$ & 29 & 18 & 11 & 0.197 \\
\hline$(+)$ & 61 & 29 & 32 & \\
\hline \multicolumn{5}{|l|}{ Cirrosis } \\
\hline Negative & 16 & 10 & 6 & 0.364 \\
\hline Positive & 74 & 37 & 37 & \\
\hline \multicolumn{5}{|l|}{$\operatorname{AFP}(\mathrm{ng} / \mathrm{ml})$} \\
\hline$\leq 50$ & 37 & 19 & 18 & 0.890 \\
\hline$>50$ & 53 & 28 & 25 & \\
\hline \multicolumn{5}{|l|}{ Sgtb } \\
\hline Low expression & 69 & 29 & 40 & $<0.001$ \\
\hline High expression & 21 & 18 & 3 & \\
\hline
\end{tabular}

of Remmele and Stegner. SGTB expression was considered high when scores were $>3$, and low when scores were $\leq 3$. Of these 90 patients, the survival rate of the SGTB low-expresser group was far below the SGTB high-expresser group (Table 2). When all variables were compared separately to survival status, SGTB $(\mathrm{P}<0.001)$ and histological grade $(\mathrm{P}<0.001)$ were clearly influenced survival status (Table $2 \mathrm{~A}$ ). Interestingly, gender factor also shows the correlation with patients' survival probably be attributed to high incidence of liver cancer in male. As the low expression of SGTB was associate with gender, statistical analysis on the male patients was further performed. Results proved SGTB $(\mathrm{P}=0.001)$ and histological grade $(\mathrm{P}=0.001)$ influenced survival significantly which was consistent with above research (Table 2B). In univariate analysis either on the whole 90 patients or just on the male, the Kaplan-Meier survival curves showed that low SGTB expression related to a poor survival with statistical significance (Fig3). The Cox's proportional hazards regression model proved that SGTB and histological grade were independent prognostic factors in the 90 patients with HCC (Table 3 ).
B. Survival status and clinicopathological parameters in 74 male HCC specimens

\begin{tabular}{|c|c|c|c|c|}
\hline \multirow{2}{*}{ Parameters } & \multirow{2}{*}{ Total } & \multicolumn{2}{|c|}{ Survival status } & \multirow{2}{*}{$\mathrm{p}^{\mathrm{a}}$} \\
\hline & & Alive & Dead & \\
\hline \multicolumn{5}{|l|}{ Age(years) } \\
\hline$\leq 50$ & 41 & 20 & 21 & 0.585 \\
\hline$>50$ & 33 & 14 & 19 & \\
\hline \multicolumn{5}{|l|}{ Histological grade } \\
\hline Well & 8 & 8 & 0 & 0.001 \\
\hline Mod & 28 & 15 & 13 & \\
\hline Poor & 38 & 11 & 27 & \\
\hline \multicolumn{5}{|l|}{ Metastasis } \\
\hline Positive & 13 & 3 & 10 & 0.068 \\
\hline Negative & 61 & 31 & 30 & \\
\hline \multicolumn{5}{|l|}{ Tumor size } \\
\hline$\leq 5$ & 42 & 27 & 15 & $<0.001$ \\
\hline$>5$ & 32 & 7 & 25 & \\
\hline \multicolumn{5}{|l|}{ HBsAg } \\
\hline$(-)$ & 25 & 14 & 11 & 0.215 \\
\hline$(+)$ & 49 & 20 & 29 & \\
\hline \multicolumn{5}{|l|}{ Cirrosis } \\
\hline Negative & 11 & 6 & 5 & 0.535 \\
\hline Positive & 63 & 28 & 35 & \\
\hline \multicolumn{5}{|l|}{$\operatorname{AFP}(\mathrm{ng} / \mathrm{ml})$} \\
\hline$\leq 50$ & 31 & 15 & 16 & 0.721 \\
\hline$>50$ & 43 & 19 & 24 & \\
\hline \multicolumn{5}{|l|}{ SGTB } \\
\hline Low expression & 60 & 22 & 38 & 0.001 \\
\hline High expression & 14 & 12 & 2 & \\
\hline
\end{tabular}

a Statistical analyses were performed by the Pearson $\chi^{2}$ test. $\mathrm{P}<0.05$ was considered significant 


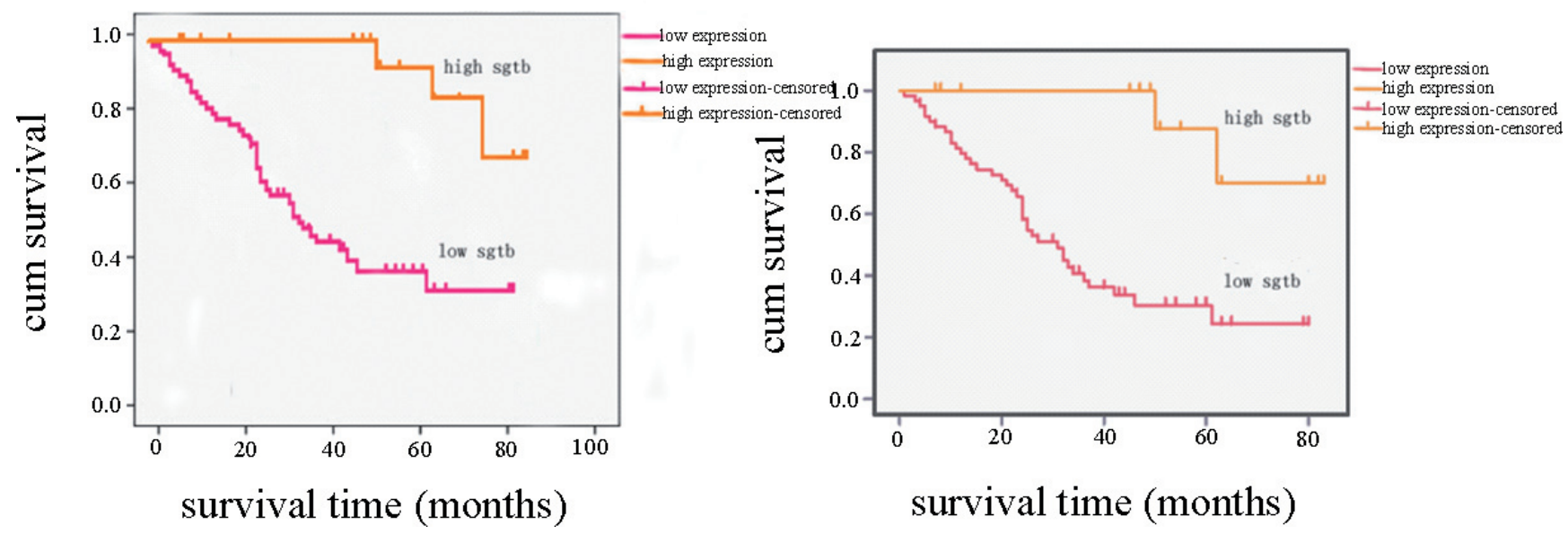

Figure 3. A Kaplan-Meier survival curves for low SGTB expression versus high SGTB expression in 90 patients of HCC showed a highly significant separation $(\mathbf{P}<0.001$, logrank test). B Kaplan-Meier survival curves for low SGTB expression versus high SGTB expression in 74 male patients of HCC showed a highly significant separation $(\mathrm{P}<0.001$, logrank test $)$.

\section{Discussion}

$\mathrm{HCC}$ is a potentially fatal consequence of $\mathrm{HBV}$ infection. Approximately $25 \%$ of chronically $\mathrm{HBV}$-infected individuals will develop HCC [15]. Chronic carriers of HBV have up to a 30-fold increased risk of HCC [16]. Clinical, pathological, epidemiological, molecular, and animal studies clearly show that HBV infection is the most important risk factor for HCC and that it is the etiology underlying approximately $50 \%$ of all cases $[17,18]$. Viral factors associated with a greater risk of HCC include HBeAg positivity, serum HBV DNA levels, and $\mathrm{HBV}$ genotypes. Increasing evidence suggests that persistent $\mathrm{HBV}$ replication is a predictor of HCC [3]. Thus, efforts to prevent $\mathrm{HCC}$ in chronic hepatitis $\mathrm{B}(\mathrm{CHB})$ patients should begin by controlling $\mathrm{HBV}$ infection and resistance to $\mathrm{HBV}$ replication maybe more effective.

In present study, we find SGTB down regulated obviously in HCC. Although the mechanism of low SGTB expression increases the risk of HCC occurrence remains unclear, it influence the infections of HBV according to our statistical correlation analysis of the clinical factors. Consequently, SGTB down regulation leading to occurrence of HCC could be achieved by increasing the risk of HBV infection.

Previous studies have reported that SGTB is a heat-shock protein cognate 70 (Hsc70) co-chaperone [12]. Hsc70 is an ATP-binding protein of the heat stress protein 70 (Hsp70) family [19]. Human Hsc70 protein contains an ATP-binding domain (ABD) (nucleotides [nt] 1 to 1146; amino acids [aa] 1 to 382), a peptide-binding domain (PBD) (nt 1155 to 1629; aa 385 to 543), and a C-terminal domain (CTD) (nt 1620 to 1938; aa 540 to 646) $[22,23]$. Within the $\mathrm{PBD}$, there are a nuclear localization signal (NLS) region (nt 1419 to 1476; aa 473 to 492) and a coiled-coil (CC) region (nt 1533 to 1608; aa 511
Table 3. Contribution of various potential prognostic factors to survival by Cox regression analysis in 90 HCC specimens.

\begin{tabular}{lccc}
\hline & Hazard ratio & 95\%Confidence interval & $\mathrm{p}^{\mathrm{a}}$ \\
\hline Gender & 0.273 & $0.074-1.005$ & 0.051 \\
Age(years) & 1.344 & $0.640-2.824$ & 0.435 \\
Histological grade & 2.011 & $1.026-3.943$ & 0.042 \\
Metastasis & 0.969 & $0.269-3.488$ & 0.962 \\
Tumor size & 0.244 & $0.101-0.593$ & 0.002 \\
HBsAg & 1.377 & $0.510-3.722$ & 0.528 \\
Cirrhosis & 0.965 & $0.295-3.162$ & 0.953 \\
AFP & 1.262 & $0.601-2.651$ & 0.539 \\
SGTB & 0.191 & $0.047-0.782$ & 0.021 \\
\hline
\end{tabular}

a Statistical analyses were performed by the log-rank test. $\mathrm{P}<0.05$ was considered significant.

to 536$)[23,24]$. It is constitutively expressed and only mildly induced during stress situation while Hsp70 is highly inducible during stress [20]. Hsc70 was found to be required for the reverse transcription process in experiments using duck HBV DNA polymerase $[21,22]$.

SGT contains three domains including an amino-terminal domain, a central tetratricopeptide repeat (TPR) domain, and a carboxyl-terminal domain [25]. The TPR motifs might give an indication to its function. Since there is extensive evidence demonstrating that TPR motifs are important in the function of chaperones, cell cycle, transcription and protein transport complexes [26]. SGTB is actually an isoform of SGT with $60 \%$ amino acid sequence homology harboring similar binding properties. Some data indicate that SGTs couple Hsc70 to client proteins and downstream-acting proteins [12]. It binds to Hsc70 via a two-carboxylate clamp mechanism involving the 
TPR domain [12]. Since SGTB was down regulated in HCC, we would like to know whether SGT expression changes. The paired HCC and normal liver tissues' SGT expression was evaluated with western blotting method. Actually, the results did show the differential expression. The role of its abnormal expression in HCC is followed up. Most important results show that the ability of SGT to interact with Hsc70 and to negatively influence the capacity of Hsc70 together with DnaJ to refold an unfolded substrate indicates a role as a negative regulator of Hsc70 function [26]. The C terminus of Hsc70 was the binding domain interacting with SGT [25]. In addition, recent researches suggested the Hsc70 mutant with deletion of the CTD or NLS caused partial loss of support for HBV replication compared to wild-type Hsc70 [6]. Since our data show the correlation between SGTB expression and HBV infection, we speculate that CTD of Hsc70 occupied by SGTB may partially prevent it from interacting with HBV, then repress the replication of HBV in host cells, and reduce the occurrence of HCC.

Although some investigations support that direct down regulation of Hsc70 in the host would inhibit HBV replication in either wild-type or drug-resistant strains [6]. However, unlike majority other families of Hsp70 expressed only at low or undetectable levels in most unstressed normal cells and tissues, which is rapidly induced by variety of physical and chemical stresses [7], Hsc70 is the only cytosolic Hsp70 protein that is abundantly and ubiquitously expressed in all cells [27]. Therefore, utilizing Hsc70 as the target of drug may disturb the functions of normal host cells. Comparatively directing SGTB probably has more practical value.

Besides that, the interaction between SGTB and Hsc70 probably modulate the function of $\mathrm{p} 53$ which is often expressed aberrantly in HCC. Previous evident a good correlation exists between high levels of p53 and the presence of p53-Hsc70 complexes [28]. Over expression of p53 or structural alterations of p53 likely mediate the interaction of $\mathrm{Hsc70}$ and p53, which is a functionally normal response to an altered oncogene product. Hsc70-p53 complexes could result in the activation of a pathway that leads to the transformed phenotype [28]. If this pathway is activated in the development of HCC, overexpression of SGTB may disturb the formation of p53-Hsc70 complexes to some extent by binding to Hsc70 competitively, and have negative effects on HCC.

In line with the correlation analysis of clinical factors, SGTB expression was also obviously correlated with histological grade $(\mathrm{P}<0.001)$ and gender. Although there is no present survey reveals the function of SGTB in cell differentiation directly, an integrated approach of differential mass spectrometry and gene oncology analysis identified SGT as one of novel proteins regulating neuronal differentiation and survival, it was up regulated during NGF-induced PC12 cell neuronal differentiation process [29]. SGTB may play a similar role in the differentiation of liver cells. However, knowledge of the precise dynamic molecular events remains far from complete. Interestingly, the reason of SGTB expression correlated with gender remains unclear. Our reports on the male patients are consistent with the investigations on the whole samples. Further study on female should be followed up.

Taken together, our findings demonstrated that compared with paracancerous tissue, SGTB was significantly downregulated in HCC, its expression in HCC shows remarkable relations with histological grade $(\mathrm{P}<0.001)$ and gender. Low SGTB expression related to a poor survival with statistical significance.

Acknowledgments: This work was supported by the National Basic Research Program of China (973 Program, No.2011CB910604, and No.2012CB822104); the National Natural Science Foundation of China (No. 81172879); Natural Science Foundation of Jiangsu province (No.BK2009156); A Project Funded by the Priority Academic Program Development of Jiangsu Higher Education Institutions (PAPD).

\section{References}

[1] El-SEARG HB, RUDOLPH KL Hepatocellular carcinoma: epidemiology and molecular carcinogenesis. Gastroenterology 2007; 132: 2557-2576. http://dx.doi.org/ 10.1053/j.gastro.2007.04.061

[2] WILLIAMS R Global challenges in liver disease. Hepatology 2006; 44: 521-526. http://dx.doi.org/10.1002/hep.21347

[3] KIM BK, HAN KH, AHN SH Prevention of Hepatocellular Carcinoma in Patients with Chronic Hepatitis B Virus Infection. Oncology 2011; 81: 41-49. http://dx.doi. org/10.1159/000333258

[4] FRYDMAN J Folding of newly translated proteins in vivo: the role of molecular chaperones. Annu Rev Biochem 2001; 70: 603-647. http://dx.doi.org/10.1146/annurev. biochem.70.1.603

[5] LIU T, DANIELS CK, CAO S Comprehensive review on the HSC70 functions, interactions with related molecules and involvement in clinical diseases and therapeutic potential. Pharmacol Ther 2012; 136: 354-374. http://dx.doi. org/10.1016/j.pharmthera.2012.08.014

[6] WANG YP, LIU F, HE HW, HAN YX, PENG ZG et al. Heat Stress Cognate 70 Host Protein as a Potential Drug Target against Drug Resistance in Hepatitis B Virus. AAC 2010; 54: 2070-2077.

[7] ROHDE M, DAUGAARD M, JENSEN MH, HELIN K, NYLANDSTED J et al. Members of the heat-shock protein 70 family promote cancer cell growth by distinct mechanisms. Genes Dev 2005; 19: 570-582. http://dx.doi.org/10.1101/ gad.305405

[8] PRANGE R, WERR M, LOFFLER-MARY H Chaperones involved in hepatitis B virus morphogenesis. Biol Chem 1999; 380: 305-314. http://dx.doi.org/10.1515/BC.1999.042

[9] ZOULIM F Evaluation of novel strategies to combat hepatitis B virus targetting wild-type and drug-resistant mutants in experimental models. Antivir Chem Chemother 2001; 1: 131-142.

[10] WU SJ, LIU FH, HU SM, WANG C Different combinations of the heat-shock cognate protein 70 (hsc70) C-terminal functional groups are utilized to interact with distinct tetratr- 
icopeptide repeat-containing proteins. Biochem J 2001; 359: 419-426. http://dx.doi.org/10.1042/0264-6021:3590419

[11] KORDES E, SAVELYEVA L, SCHWAB M, ROMMELAERE J, JAUNIAUX JC et al. Identification of a novel cellular TPRcontaining protein, SGT, that interacts with the nonstructural protein NS1 of parvovirus H-1. Genomics 1998; 52: 90-94. http://dx.doi.org/10.1006/geno.1998.5385

[12] TOBABEN S, VAROQUEAUX F, BROSE N, STAHL B, MEYER GA Brain-specific Isoform of Small Glutamine-rich Tetratricopeptide Repeat-containing Protein Binds to Hsc70 and the Cysteine String Protein. J Biol Chem 2003; 278: 38376-38383. http://dx.doi.org/10.1074/jbc.M301558200

[13] REMMELE W, STEGNER HE Recommendation for uniform definition of an immunoreactive score (IRS) for immunohistochemical estrogen receptor detection (ER-ICA) in breast cancer tissue. Pathologe 1987; 8: 138-140.

[14] LING G, SUGATHAN A, MAZOR T, FRAENKEL E, WAXMAN DJ Unbiased, genome-wide in vivo mapping of transcriptional regulatory elements reveals sex differences in chromatin structure associated with sex-specific liver gene expression. Mol Cell Biol 2012; 30: 5531-5544. http://dx.doi. org/10.1128/MCB.00601-10

[15] GANEM D, PRINCE AM Hepatitis B virus infection--natural history and clinical consequences. N Engl J Med 2004; 350: 1118-1129. http://dx.doi.org/10.1056/NEJMra031087

[16] FRANCESCHI S, MONTELLA M, POLESEL J, LA VECCHIA C, CRISPO A et al. Hepatitis viruses, alcohol, and tobacco in the etiology of hepatocellular carcinoma in Italy. Cancer Epidemiol Biomarkers 2006; Prev 15: 683-689.

[17] PARKIN DM, BRAY F, FERLAY J, PISANI P Estimating the world cancer burden: Globocan 2000. Int J Cancer 2001; 94: 153-156. http://dx.doi.org/10.1002/ijc.1440

[18] HAN KH, AHN SH How to predict HCC development in patients with chronic B viral liver disease? Intervirology 2005; 48: 23-28. http://dx.doi.org/10.1159/000082091

[19] PE'REZ-VATGAS J, ROMERO P, LO'PEZ S, ARIAS CF The peptide binding and ATPase domains of recombinant Hsc70 are required to interact with rotavirus and reduce its infectivity. J Virol 2006; 80: 3322-3331. http://dx.doi. org/10.1128/JVI.80.7.3322-3331.2006

[20] GEBAUER M, MELKI R, GEHRING U The chaperone cofactor Hop/p60 interacts with the cytosolic chaperonincontaining TCP-1 and affects its nucleotide exchange and protein folding activities. J Biol Chem 1998; 273: 29475-29480. http://dx.doi.org/10.1074/jbc.273.45.29475

[21] BECK J, NASSAL M Efficient Hsp90-independent in vitro activation by $\mathrm{Hsc} 70$ and $\mathrm{Hsp} 40$ of duck hepatitis B virus reverse transcriptase, an assumed Hsp90 client protein. J Biol Chem 2003; 278: 36128-36138. http://dx.doi.org/10.1074/jbc.M301069200

[22] HU J, FLORES D, TOFT D, WANG X, NGUYEN D Requirement of heat shock protein 90 for human hepatitis $\mathrm{B}$ virus reverse transcriptase function. J Virol 2003; 78: 13122-13131. http://dx.doi.org/10.1128/JVI.78.23.13122-13131.2004

[23] MORSHAUSER RC, HU W, WANG H, PANG Y, FLYNN $\mathrm{GC}$ et al. High-resolution solution structure of the $18 \mathrm{kDa}$ substratebinding domain of the mammalian chaperone protein Hsc70. J Mol Biol 1999; 289: 1387-1403. http://dx.doi. org/10.1006/jmbi.1999.2776

[24] TSUKAHRA F, MARU Y Identification of novel nuclear export and nuclear localization-related signals in human heat shock cognate protein 70. J Biol Chem 2004; 279: 8867-8872. http://dx.doi.org/10.1074/jbc.M308848200

[25] LIU FH, WU SJ, HU SM, HSIAO CD WANG C Specific interaction of the $70-\mathrm{kDa}$ heat shock cognate protein with the tetratricopeptide repeats. J Biol Chem 1999; 274: 3442534432. http://dx.doi.org/10.1074/jbc.274.48.34425

[26] SCHANTL JA, ROZA M, JONG AP, STROUS GJ Small glutamine-rich tetratricopeptide repeat-containing protein (SGT) interacts with the ubiquitin-dependent endocytosis (UbE) motif of the growth hormone receptor. Biochem J 2003; 373: 855-863. http://dx.doi.org/10.1042/BJ20021591

[27] BECK J, NASSAL M Efficient Hsp90-independent in vitro activation by $\mathrm{Hsc70}$ and $\mathrm{Hsp} 40$ of duck hepatitis B virus reverse transcriptase, an assumed Hsp90 client protein. J Biol Chem 2003; 278: 36128-36138. http://dx.doi.org/10.1074/jbc. M301069200

[28] HINDS PW, FINLAY CA, FREY AB, LEVINE AJ Immunological Evidence for the Association of p53 with a Heat Shock Protein, Hsc70, in p53-plus-ras-Transformed Cell Lines. Mol Cell Biol 1987; 7: 2863-2869.

[29] KOBAYASHI D, KUMAGAI J, MORIKAWA T, WILSONMORIFUJI M, WILSON A et al. An Integrated Approach of Differential Mass Spectrometry and Gene Ontology Analysis Identified Novel Proteins Regulating Neuronal Differentiation and Survival. Mol Cell Proteomics 2009; 8: 2350-2367. http://dx.doi.org/10.1074/mcp.M900179-MCP200 